For the final, publisher's version see:

http://dx.doi.org/10.1111/j.1600-0706.2011.19774.x

(C) 2011 The Authors. Oikos (C) 2011 Nordic Society Oikos

\title{
Stochastic LTRE analysis of the effects of herbivory on the population dynamics of a perennial grassland herb
}

Hans Jacquemyn ${ }^{1 *}$, Rein Brys ${ }^{2}$, Raziel Davison ${ }^{3}$, Shripad Tuljapurkar ${ }^{3}$ and Eelke Jongejans ${ }^{4}$

1) Division of Plant Ecology and Systematics, University of Leuven, Kasteelpark Arenberg 31, B-3001 Heverlee, Belgium.

2) Research Institute for Nature and Forest, Kliniekstraat 25, B-1070 Brussels, Belgium.

3) Department of Biology, Stanford University, Stanford, CA 94305, USA.

4) Radboud University Nijmegen, Institute for Water and Wetlands Research, Department of Experimental Plant Ecology, Heyendaalseweg 135, 6525 AJ Nijmegen, The Netherlands.

* Author for correspondence:

Hans Jacquemyn

Division of Plant Ecology and Systematics

University of Leuven

Kasteelpark Arenberg 31, B-3001 Heverlee, Belgium

Tel.: + 32163215 30; Fax: +32 16321968

E-mail: hans.jacquemyn@bio.kuleuven.be

\begin{abstract}
Herbivores can have strong deleterious effects on vital rates (growth, reproduction, and survival) and thus negatively impact the population dynamics of plant species. In practice, however, these effects might be strongly correlated, for example as a result of trade-offs between vital rates. To get better insights into the effects of herbivory on the population dynamics of the long-lived grassland plant Primula veris population projection matrices were constructed from demographic data collected between 1999 and 2008 (nine annual transitions). Data were collected in two large grassland populations, each of which was subjected to two treatments (grazing by cattle vs. a mowing treatment), yielding a total of 36 matrices. We applied a lower-level vital rate life table response experiment (LTRE) using the small noise approximation (SNA) of the stochastic population growth rate to disentangle the contributions of changes in mean vital rates, variability in vital rates, correlations between vital rates and vital rate elasticities to the difference in the stochastic growth rate. Stochastic growth rates ( $a=\log \lambda_{\mathrm{S}}$ ) were significantly lower in grazed than in mown plots ( $a=0.0185$ and 0.1019, respectively). SNA LTRE analysis showed that contributions of differences in mean vital rates by far made the largest contribution to the observed difference in $a$ between grazed and control plots. In particular, changes in sexual reproduction rates made the largest contributions to lower the stochastic growth rate in grazed plots: both adult flowering probabilities and flower and seed production were importantly lower in grazed populations, but these negative effects were largely buffered by increased establishment and seedling survival rates. Among the stochastic terms of the SNA decomposition, contributions of changes in covariance and correlations between vital rates had the largest impact, whereas contributions of changed elasticities were smaller. The strongest correlation driver was the association between adult survival and seedling establishment, suggesting that environmental
\end{abstract}


conditions favouring adult survival also are beneficial for seedling establishment. Overall, our results show that herbivory had a strong negative effect on the long-term population growth rate of $P$. veris that was primarily mediated by differences in fecundity (flower and seed production) and germination.

Key words: herbivory; life table response experiment (LTRE); Primula veris; small noise approximation (SNA); stochastic population growth rate $\left(\lambda_{s}\right)$.

\section{Introduction}

The precise factors that determine the population dynamics and long-term population growth rate of plant species subject to grazing are diverse, complex and often interdependent. In general, the impact of grazing animals on plant population dynamics varies depending on the plant species that is grazed and on the animal species that consumes the plant (Maron and Crone 2006). Grassland plants are particularly prone to the negative effects of consumers, whereas forest herbs are less affected (Maron and Crone 2006). On the other hand, the impact of grazers is not dependent on life-history traits such as reproductive mode or longevity (Maron and Crone 2006, but see Hayes and Holl 2003).

In practice for natural populations, it is difficult to untangle the direct consumptive effects of herbivores from indirect effects, as they often appear to be interrelated (Crawley 1983, McNaughton 1983). Given that correlations between vital rates may have a strong impact on basic demography and long-term population viability (Wisdom et al. 2000, Menges 2000, Jongejans et al. 2010), better insights into these correlations are indispensable for assessing the underlying dynamics of plant populations subject to grazing. Reductions in seed production due to grazing, for example, may strongly impact the number of germinating seeds in the next season, but treading by grazing animals may increase seedling establishment and survival as a result of the higher availability of suitable micro-sites. Similarly, reductions in growth may affect the probability of flowering, but at the same time incur costs to survival, growth and reproduction in the next season, leading to trade-offs between current reproduction and future survival, growth or fecundity (Stearns 1989).

Most studies investigating the effects of herbivory on the population dynamics of plant species have a short duration ( $<4$ years) (Menges 2000, Maron and Crone 2006, Crone et al. 2011), and therefore may fail to detect trade-offs in life history traits. Particularly in longlived, iteroparous species with overlapping generations, assessing the impact of trade-offs on plant population dynamics has proved challenging (Doak 1992, Obeso 2002). Due to their short duration, most studies also largely ignore the fact that demographic rates may vary over time. The abundance of grazers and grazing intensity, and the timing of grazing may vary substantially from one year to the next, which in turn may lead to strong variation in vital rates between years (Crawley 1983, Buckley et al. 2010) and therefore contribute negatively to the long term growth rate of grazed populations (Cohen 1979). Moreover, differences in environmental conditions between years may also directly impact population dynamics and these impacts may be mediated by grazing (Bastrenta et al. 1995).

In this case, classic life table response experiments (LTREs) using deterministic estimates of the population growth rate, such as the dominant eigenvalue of the mean projection matrix $\left(\lambda_{0}\right)$ or the intrinsic growth rate $\left(r=\log \lambda_{0}\right)$, may fail to accurately assess the effect of herbivores on the long-term growth rate (Cohen 1977, Tuljapurkar and Orzack 1980). Instead, the stochastic growth rate, $a=\log \lambda_{s}=E\left\{\log \lambda_{0}(t)\right\}$, provides a better way to describe the long-term demographic behaviour of plant populations in varying environments 
(Tuljapurkar 1990), whereas recent extensions of life table response experiments for stochastic population growth allow us to assess the various demographic and environmental factors that contribute most to variation in the stochastic growth rate (Caswell 2010, Davison et al. 2010, 2011).

In this study, we investigated the impact of herbivory on the population dynamics of the long-lived perennial grassland plant Primula veris. In a previous study, Brys et al. (2011) showed that herbivory by grazing animals (cattle) had a strong impact on the size of individuals of this species and that belowground biomass of grazed plants was about $20 \%$ smaller than that of plants in the same population that were exposed to mowing. The number of leaves and the size of leaves were significantly smaller in grazed plants than among plants in mown plots. Reduced numbers of leaves and smaller leaf areas affect survival probabilities, and may also impact future flowering behaviour, as the amount of carbohydrates that can be relocated to belowground storage organs decreases with leaf area, possibly leading to resource depletion and reduced performance in the next year. Short-term experiments in which a proportion of the leaves was removed at different times in the growing season have indeed shown that removal of $50 \%$ of the leaves during flowering (early defoliation) negatively affected current reproductive performance (fruit set and total seed production) and future growth, whereas middle defoliation (removal of $50 \%$ of the leaves during fruit development) only reduced future flowering probability and growth, and late defoliation (removal of $50 \%$ of the leaves during fruit maturation) did not affect any fitness component (García and Ehrlén 2002). These observations suggest that damage to above-ground tissue during the growing season not only results in the destruction of flowering stalks and fruits, but may also reduce flowering probabilities and performance of adult individuals in the next growing season, depending on the developmental stage of the plant (García and Ehrlén 2002, Brys et al. 2004). However, the long-term effects of herbivory on the population dynamics remain poorly understood.

For the present study, population projection matrices were constructed from demographic data collected between 1999 and 2008 (nine annual transitions). Data were collected from two populations, each of which was subjected to two treatments (cattle grazing vs. mowing), yielding a total of 36 matrices. We applied lower-level vital rate LTRE analyses using the small noise approximation of the stochastic growth rate (Davison et al. 2011) to untangle the direct consumptive effects of herbivores from a variety of indirect effects acting on the population dynamics of this grassland species. This technique has the particular advantage that it allows us to quantify the effects of differences in mean vital rates, in variability in vital rates, in correlations between vital rates and in elasticities of vital rates (Davison et al. 2011).

\section{Material and Methods}

\section{Study species}

Primula veris (Primulaceae) is a small perennial herb with a wide distribution in Europe (Brys and Jacquemyn 2009). It typically occurs in nutrient-poor, calcareous grasslands, in which it can be locally abundant, but it may also be found in dune grasslands and hay-meadows. Early in spring, plants produce a rosette of several leaves and one (though, rarely, two or more) flowering stalks bearing between 4 and 15 yellow flowers displayed in an umbel (García and Ehrlén 2002). Flowers are distylous (Wedderburn and Richards 1990) and mainly pollinated by bees and bumblebees (Ornduff 1980, Brys and Jacquemyn 2009). In the study area, flowering starts at the end of April and lasts about three to four weeks. Seeds ripen 8-10 weeks after fertilization and seed shed takes place from mid-July to September. Seeds lack 
any specific dispersal mechanisms and in most cases fall in the direct neighbourhood $(<15$ $\mathrm{cm}$ ) of their mother plants (Richards and Ibrahim 1978).

The majority of seeds survive winter and germinate in spring (from the end of April until mid-May). Although seeds can accumulate in the soil seed bank (Milberg 1994), our own experiments suggest that recruitment from the seed bank is very limited (Brys and Jacquemyn 2009, Jacquemyn et al. 2011). This species is characterised by the occurrence of a rhizome, which produces numerous fibrous roots that thrust through living leaf bases and which can be up to $15 \mathrm{~cm}$ long. This rhizome is thought to function as a storage organ and may buffer compensatory responses following herbivory and/or reproductive costs in the short term (Brys and Jacquemyn 2009).

\section{Data collection and experimental design}

To investigate the effects of herbivory on the population dynamics of $P$. veris the fate of each $P$. veris individual was monitored annually between 1999 and 2008. The design of this experiment is detailed by Brys et al. (2011). Two comparable sites, both displaying optimal growth conditions and containing $>10.000$ flowering individuals of $P$. veris, were selected in Voeren (Eastern Belgium). The populations are about $1 \mathrm{~km}$ apart and located in calcareous grasslands on a south-facing slope (inclination $20^{\circ}$ ). Before sites were selected, it was ascertained that they had a similar history of grassland management.

At each site, ten permanent plots $\left(3 \times 3 \mathrm{~m}^{2}\right)$ were established in the winter of 1999 , yielding a total of 20 plots. All plots were laid out in the central and most homogenous part of each population. Half of the plots were grazed and the other half were fenced and mown annually at the end of the growing season (the second half of August). At this time, $P$. veris leaves had already started to degenerate and most of the aboveground resources were reallocated to the rhizomatous roots. Cattle grazing started at the end of May and lasted intermittently until the end of September. Average cattle density numbered 15 cows ha ${ }^{-1}$ and was similar across sites. Fenced plots were mown mechanically $(2-4 \mathrm{~cm}$ above the ground surface) and all litter was removed afterwards. Each of the plots received the same management throughout the entire study period (1999-2008), but the timing of grazing varied throughout the study period. Whereas in the beginning of the study period (1999-2001) grazing started already in May, later during the experiment cows were allowed to graze only from the middle of June (see Brys et al. 2004 for more details).

At the beginning of the experiment (1999), each plant was meticulously mapped using a $5 \times 5 \mathrm{~cm}^{2}$ grid and its life-history state was determined. Following Brys et al. (2004), plants were classified into one of four categories: seedlings (all plants younger than one year); juveniles (more than 1 year and the number of leaves $\leq 3$ and/or length of the largest leaf $<2$ $\mathrm{cm}$ ); vegetative individuals (more than 1 year and the number of leaves $>3$ and /or length of the largest leave $\geq 2 \mathrm{~cm}$ ); and reproductive individuals (more than 1 year and bearing flowers). For a detailed description of the life cycle and all life cycle transitions we refer to Brys et al. (2004).

To avoid edge effects and damage due to demographic monitoring, only the central 1 $\times 1 \mathrm{~m}^{2}$ area within each $3 \times 3 \mathrm{~m}^{2}$ plot was surveyed for demographic analyses. In subsequent years, all plots were monitored again, and the fate of each mapped plant was determined. New seedlings arising in the population were also mapped annually and the state of each plant was characterized during ten consecutive years. During this period, a total of 4594 plants was monitored. For flowering plants, the number of flowers per plant and the number of seeds per fruit were determined each year for twenty plants per treatment and site. Plants were randomly selected in the plots, and for each selected plant the number of flowers was counted. 
fruit the number of seeds was counted. For each year and treatment, the average number of flowers and average seed set were used in all subsequent analyses.

\section{Data analysis}

For each year, site and treatment we constructed population projection matrices, resulting in a total of 36 matrices (see Appendix S1) describing annual population projections (Caswell 2001). In these projections, $n_{t}$ is the number of individuals in each stage class at time $t$ and $\mathbf{A}$ is the population projection matrix $\left(\mathbf{A}=\left\{a_{i j}\right\}\right)$. Matrix elements $a_{i j}$ describe the annual percapita contribution of stage $i$ individuals made by stage $j$ individuals and $\left(n_{t+1}=A n_{t}\right)$ describes the population projection:

$$
n_{t+1}=A n_{t}=\left(\begin{array}{c}
L(t+1) \\
J(t+1) \\
V(t+1) \\
F(t+1)
\end{array}\right)=\left(\begin{array}{cccc}
0 & 0 & 0 & \mu \pi \varepsilon \\
\sigma_{\mathrm{L}}\left(1-\gamma_{\mathrm{L}}\right) & \sigma_{\mathrm{J}}\left(1-\gamma_{\mathrm{J}}\right) & 0 & 0 \\
\sigma_{\mathrm{L}} \gamma_{\mathrm{L}} & \sigma_{\mathrm{J}} \gamma_{\mathrm{J}}\left(1-\varphi_{\mathrm{J}}\right) & \sigma_{\mathrm{V}}\left(1-\varphi_{\mathrm{V}}\right) & \sigma_{\mathrm{F}}\left(1-\varphi_{\mathrm{F}}\right) \\
0 & \sigma_{\mathrm{J}} \gamma_{\mathrm{J}} \varphi_{\mathrm{J}} & \sigma_{\mathrm{V}} \varphi_{\mathrm{V}} & \sigma_{\mathrm{F}} \varphi_{\mathrm{F}}
\end{array}\right)\left(\begin{array}{c}
L(t) \\
J(t) \\
V(t) \\
F(t)
\end{array}\right)
$$

Here, $L$ is the number of seedlings, $J$ the number of juveniles, $V$ the number of vegetative plants and $F$ the number of flowering plants in a given year. Because matrix elements are compounds of different vital rates, demographic comparisons among populations were made using vital rates rather than matrix elements and matrix elements were explicitly written as functions of different vital rates (Caswell 2001, Franco and Silvertown 2004). In equation 1, $\sigma$ refers to survival, $\gamma$ to growth conditional on survival, and $\varphi$ refers to the probability of a plant flowering in the next year. The terms in the fecundity element $\left(a_{14}\right)$ refer to the average number of flowers $(\mu)$, the average number of seeds per fruit $(\pi)$ and the proportion of seeds that germinate and successfully establish as a seedling $(\varepsilon)$.

Based on these matrices, we calculated the long-term stochastic growth rate $(a=\log$ $\lambda_{\mathrm{S}}$ ) in two ways for each site and treatment: 1 ) by simulation (of 100,000 years, discarding the first 2,000 years to exclude initial transient dynamics) and 2) by using the small noise approximation (Tuljapurkar 1990). In the latter case, the stochastic growth rate can be written as the deterministic growth rate minus a product containing vital rate elasticities (e), coefficients of variation $(c)$ and correlations between vital rates $(\rho)$ (Haridas and Tuljapurkar 2005, Jongejans et al. 2010, Davison et al. 2011):

$$
a=\log \lambda_{s} \approx r-\frac{1}{2} \sum_{k, l} e_{k} e_{l} c_{k} c_{l} \rho_{k, l}
$$

The second term in (2) describes the stochastic component of the population growth rate and shows depreciation of the deterministic growth rate by each of the different terms.

We applied vital rate LTRE analysis using the small noise approximation of the stochastic growth rate (Davison et al. 2011) to study the impact of herbivory on the overall population growth rate and to assess contributions of mean vital rates, variance in vital rates and correlations between vital rates to differences in the stochastic growth rate. For these analyses we used vital rates averaged over the two sites for each treatment-year combination. Following Davison et al. (2011), the difference in stochastic growth rates $(\Delta a)$ between the mowing and grazing treatment can be written as a difference of a sum of products:

$$
\Delta a=a^{(g)}-a^{(m)} \approx r^{(g)}-r^{(m)}-\frac{1}{2}\left(\sum_{k, l}\left\{e_{k} e_{l} c_{k} c_{l} \rho_{k, l}\right\}^{(g)}-\sum_{k, l}\left\{e_{k} e_{l} c_{k} c_{l} \rho_{k, l}\right\}^{(m)}\right)
$$

Using the Kitagawa decomposition (Kitagawa 1955), Davison et al. (2011) showed that this difference can be approximated by the summation of four components:

1) contributions of differences in vital rate means: $\sum_{k} \bar{e}_{k}\left(\log \mu_{k}^{(g)}-\log \mu_{k}^{(m)}\right)$ 
2) contributions of differences in vital rate elasticities: $-\frac{1}{2} \sum_{k, l} \overline{\left[c_{k} c_{l} \rho_{k l}\right]} \Delta\left\{e_{k} e_{l}\right\}$

3) contributions of differences in coefficients of variation: $-\frac{1}{2} \sum_{k, l} \overline{\left[e_{k} e_{l}\right]}\left(\bar{\rho}_{k, l} \Delta\left\{c_{k} c_{l}\right\}\right)$

4) contributions of differences in correlations: $-\frac{1}{2} \sum_{k, l} \overline{\left[e_{k} e_{l}\right]}\left(\overline{\left[c_{k} c_{l}\right]} \Delta\left\{\rho_{k, l}\right\}\right)$

Please note that this double Kitagawa decomposition of the stochastic term (resulting in the latter three contributions) is a perfect decomposition that contains all the components of stochastic population growth (Davison et al. 2011).

\section{Results}

\section{Flower and seed production}

The mean number of flowers per plant was significantly smaller in grazed than in mown treatments $\left(F_{1,36}=88.66, P<0.0001\right)$, but it was significantly different between sites $\left(F_{1,36}=\right.$ $0.12, P=0.73$ ) (see Appendix A for vital rate values for all site-treatment-year combinations). Similarly, average seed production per fruit was significantly higher in mown plots than in grazed plots $\left(F_{1,36}=92.67, P<0.0001\right)$, but did not differ between sites $\left(F_{1,36}=0.18, P=\right.$ $0.67)$. There were also no significant interaction effects between site and treatment $\left(F_{1,36}=\right.$ 0.08 and $0.51, P>0.05$ ). Plants produced an average of 4.7 flowers in grazed treatments, whereas in mown treatments plants had, on average, 8.7 flowers. Similarly, the average number of seeds per fruit varied between 12 and 23 in grazed plots (mean: 16.9), and between 23 and 45 in mown plots (mean: 36.8).

\section{Matrix analyses}

The effects of grazing, compared to mowing, were similar between sites. In grazed plots, annual projected deterministic population growth rates varied between 0.8402 and 1.1529 in Site 1 and between 0.6538 and 1.2345 in Site 2, whereas population growth rates of the mown treatments varied between 0.9924 and 1.2950 in Site 1 and between 0.9531 and 1.3224 in Site 2 . The corresponding intrinsic growth rates $\left(r=\log \lambda_{0}\right.$; calculated with mean vital rates) were, respectively, 0.0285 and 0.0322 in grazed sites, and 0.0994 and 0.1202 in mown sites. Consistent with earlier findings (Buckley et al. 2010) and with theoretical expectations (Cohen 1979), simulated stochastic growth rates ( $a=0.0110$ and 0.0124 in grazed sites, and 0.0861 and 0.1117 in mown sites) were consistently smaller than those of the corresponding deterministic growth rates.

\section{SNA LTRE analyses}

Small-noise approximations were close to the simulated stochastic growth rates $\left(a_{\text {simulated }}=\right.$ $0.0187, a_{\mathrm{SNA}}=0.0234$ for grazed plots; $a_{\text {simulated }}=0.1018, a_{\mathrm{SNA}}=0.1069$ for mown plots, respectively). Overall, LTRE decomposition using the SNA approximation also fitted the difference in stochastic growth rates well: the difference between the simulated $\Delta a=a^{(g)}$ $a^{(m)}$ and the SNA-LTRE sum was only $0.55 \%$ (Fig. 1). Decomposition of the stochastic growth rates of grazed vs. mown populations showed that differences were mainly due to mean vital rates. However, contributions of stochastic component were important, since their 
exclusion worsens model fit more than tenfold to a 5.79\% difference (Fig. 1). The largest stochastic contributions were made by differences in correlations between vital rates in grazed vs. mown populations and by differences in variability of vital rates (Fig. 1). Contributions of differences in elasticities, on the other hand, were smaller (Fig. 1).

The contributions of means showed that vital rates related to fecundity made by far the largest contributions (Fig. 2). There was a large positive effect of higher seedling establishment in grazed sites, but this was outweighed by the pronounced negative contribution of lower flower and seed production in grazed sites. Furthermore, the lower probability of a vegetative plant flowering and of a flowering plant remaining in flower made a substantial negative contribution among grazed sites. Interestingly, in grazed plots higher seedling and juvenile survival had a positive, albeit small contribution to differences in stochastic population growth rates, whereas lower survival of non-flowering adults had a negative effect (Fig. 2). Finally, differences in growth of seedlings and juveniles made no noticeable contribution.

The stochastic components contributing most to the difference in stochastic population growth rates of grazed vs. mown populations were the correlations among vital rates and variability of vital rates. In particular, variability in vegetative adult survival had a strong negative contribution to differences in stochastic population growth rates in grazed compared to mown populations. Similarly, the correlation between survival of non-flowering adults $\left(\sigma_{\mathrm{V}}\right)$ and seedling establishment $(\varepsilon)$ had a large negative effect on $\Delta a$. This correlation was negative $(\rho=-0.57)$ in mown plots, but positive $(\rho=0.52)$ in grazed plots (Fig.3). The strong contribution was partly because of the large $\Delta \rho$, partly because $\sigma_{\mathrm{V}}$ had the largest mean elasticity value ( $\bar{e}=0.497)$, and partly because $\varepsilon$ had an above-average $\mathrm{CV}(\bar{c}=0.509)$. Grazed populations also suffered lower growth rates due to negative contributions of differences in the correlations between the survival of juveniles and non-flowering adults $\left(\sigma_{J}\right.$ and $\left.\sigma_{\mathrm{V}}\right)$ as well as between adult flowering probabilities $\left(\varphi_{\mathrm{V}}\right.$ and $\left.\varphi_{\mathrm{F}}\right)$ and seed set $(\pi)$ (contributions are listed in order of decreasing impact: $\sigma_{\mathrm{V}^{-}} \varepsilon, \sigma_{\mathrm{F}}-\varepsilon, \sigma_{\mathrm{J}}-\sigma_{\mathrm{V}}, \sigma_{\mathrm{J}^{-}} \varphi_{\mathrm{V}}, \varphi_{\mathrm{F}}-\pi$ and $\varphi_{\mathrm{V}^{-}}$ $\pi)$. However, $76 \%$ of the total $(-0.0064)$ negative impact of grazing that was due to higher correlation coefficients was buffered by the combined positive effect $(+0.0049)$ of lower correlation coefficients in the grazed plots (Fig. 1).

\section{Discussion}

\section{Disentangling the contribution of mean effects and stochastic factors}

Consistent with previous studies (reviewed in Maron and Crone 2006), herbivory had a strong and significant impact on the population dynamics and long-term growth rate of the perennial grassland herb $P$. veris. Although other studies have tried to untangle the different effects of herbivory on the population dynamics of this species (e.g. Garcia and Ehrlén 2002, Brys et al. 2004, Ehrlén et al. 2005), this is the first to consider different aspects of the life cycle simultaneously by decomposing the projection matrix into lower level vital rates and at the same time incorporating correlations between demographic rates. Moreover, because data were collected over ten consecutive years and in different sites, this allowed us to characterize the variance-covariance structure of vital rates. Accordingly, results should be less dependent on year or site effects and therefore provide robust results and strong support to our findings.

Using a recently developed variance decomposition technique (Davison et al. 2011), we showed that differences in the long-term stochastic growth rate of grazed and mown populations were mainly due to differences in mean vital rates and to a lesser extent to differences in correlations between vital rates and variability in vital rates. Our results also showed that local selection pressures, as encapsulated in the between-treatment differences in 
vital rate elasticity values (Benton and Grant 1996), did not contribute substantially to the difference in the stochastic growth rate, suggesting that grazing does not lead to divergent selection pressures imposed on this species.

\section{The impact of grazing on population demography}

Previous analysis clearly demonstrated that grazing significantly reduced the size of $P$. veris individuals (Brys et al. 2011), which was also associated with pronounced reductions in flower and seed production. Plants in grazed conditions had about half of the flowers of plants in mown conditions, and produced on average only a third of the number of seeds. Mean total seed production can therefore be considered six times smaller in grazed conditions than in mown conditions. Our LTRE analysis showed that lower flower and seed production had a pronounced negative impact on the population growth rates of grazed vs. mown sites. Similar results have been reported for the long-lived woodland orchid Orchis purpurea, in which differences in flower and seed production caused by different light environments also had a strong effect on population growth rates (Jacquemyn et al. 2010a).

The LTRE analysis further showed that the effects of low flower and seed production were largely counterbalanced by higher seedling establishment success in grazed plots, and that this buffering reduced the difference in stochastic population growth rates between grazed and mown plots. Although there were fewer recruits per $\mathrm{m}^{2}$ in grazed than in mown plots, establishment on a per-seed basis was higher when sites were grazed. There are four mutually non-exclusive reasons that may explain these observations. First, treading by grazing cattle disturbs the soil and creates numerous small openings in the vegetation, which appeared to be suitable micro-sites for germination and survival of $P$. veris seedlings. In mown plots, where such small-scale openings in the vegetation were less apparent, seeds mostly germinated in larger openings that were often created by the activity of moles. Second, the amount of light penetrating to the soil was significantly higher in grazed than in mown plots (Jacquemyn et al. 2003), which may increase seed germination and seedling establishment. Third, seed addition experiments (Brys et al. 2005) showed that when seed density increases, the proportion of seedlings that successfully establishes decreases. Thus, with higher seed rain, per-capita establishment of seedlings is lower due to negative densitydependence. Similar results have been reported by Ehrlén et al. (2005), who found negative density-dependence in seedling establishment and also found that establishment increased when the vegetation was removed by manual clipping. Finally, it has been shown that seedling establishment under field conditions is positively related to seed weight. Lehtilä \& Ehrlén (2005), for example, showed that 57\% more seedlings were produced from heavier seeds (average seed mass $=1.24 \mathrm{mg}$ ) than from lighter ones (average seed mass $=0.73 \mathrm{mg}$ ). Although we did not measure the weight of the seeds, it is reasonable to assume that, due to seed number/seed size trade-offs, seeds in grazed sites are heavier than those from mown sites, and that this may contribute to the higher establishment success of seeds in grazed conditions.

\section{Correlations and trade-offs}

Although differences in mean vital rates contributed by far the most to the difference between stochastic growth rates of grazed and mown plots, the SNA-LTRE revealed interesting and important effects due to vital rate correlations as well. By considering differences in both deterministic and stochastic parameters, this recently developed technique can unravel such otherwise obscure effects of covariation among demographic rates. Though the stochastic effects of grazing were small, their inclusion did improve the model fit of the SNA-LTRE 
almost ten-fold, suggesting that it includes additional factors that are significant to population dynamics.

As we found with mean vital rates, we found strong buffering at the level of the vital rate correlations. The lower stochastic growth rates of grazed populations, for instance, were buffered by negative vital rate correlations that were strongly positive in mown sites. However, correlation differences that lowered the stochastic growth rate in grazed plots had a larger impact, mostly due to the positive correlation between adult survival and seedling establishment in grazed plots that was negative under mowing. Especially important contributions were made by differences in two temporal correlations. First, the correlation between $\varphi_{\mathrm{F}}$ and $\varepsilon$ was positive in mown sites, but negative in grazed sites, suggesting that differences in the drivers or cues for flowering and seedling establishment buffered grazed population growth rates. Second, $\sigma_{\mathrm{J}}-\sigma_{\mathrm{L}}$ and $\sigma_{\mathrm{V}}-\pi$ correlations were positive in mown sites, but close to zero in grazed sites, suggesting that grazed populations experienced a considerable buffering effect due to absence of positive correlations of the mortality risks of seedlings and juveniles, as well as due to the absence of synchrony between seed set and adult survival (while these vital rates were positively correlated in mown sites).

Although some of these correlation contributions are relatively easy to explain (e.g. correlation between seedling and juvenile survival in mown sites), others are less straightforward. For example, the positive correlation between seedling establishment and survival of non-flowering individuals in grazed plots may be the result of variation in grazing intensity among years. In years with high grazing pressure, many small, non-flowering plants may have died, but at the same time many flowering plants may have been damaged, which may have decreased germination due to low fruit set. In years of relatively low grazing pressures, mortality of non-flowering plants will be low, but seedling establishment will be higher due to higher fruit production. In mown sites, on the other hand, the lack of disturbances may explain the negative correlations between adult survival and seedling establishment.

\section{Costs of reproduction}

We found limited evidence for costs of reproduction affecting population dynamics of $P$. veris. Costs of reproduction have been notoriously difficult to detect in natural populations, particularly in long-lived perennial plants (Obeso 2002), and the extent to which costs affect long term population growth rates is also not well understood (but see Jacquemyn et al. 2010b). In the case of $P$. veris, non-flowering plants showed higher mortality than flowering plants and survivorship curves for non-flowering plants were always lower than those for flowering plants (results not shown). The reason for this might be that non-reproductive adults are much smaller than reproductive plants (Brys et al. 2011). Because small plants generally have lower survival chances than large plants, size-dependent mortality may explain why costs of reproduction were not observed in this system. Moreover, experiments conducted by Lethilä and Syrjänen (1995) have shown that flowering plants, when cut or pollinated with surplus pollen, actually had higher survival and flowering probabilities in the next year, suggesting that some kind of compensatory mechanism determines survival rates. García and Ehrlén (2002), who used clipping experiments and pollen addition experiments to investigate costs of reproduction in $P$. veris, also found no evidence for costs of reproduction in this species. These responses may be at least partly explained by the fact that this species invests considerable resources in above-ground growth and carbohydrate production each spring (Syrjänen \& Lehtilä 1993), and because the starch content in its roots is very low during flowering (Mestenhauser 1961). 
The SNA-decomposition of differences in stochastic growth rates allowed us to discern the impact of deterministic and stochastic factors on the long-term population growth rate in both grazed and mown sites of the perennial grassland herb P. veris. At the same time, this decomposition also allowed us to identify the vital rates that contributed most to differences in population growth rate and provided insights into contributions of correlations between vital rates. We have clearly demonstrated that grazing had a strong impact on population dynamics and that this effect was primarily due to changes in mean vital rates and to a lesser extent to differences in the variance-covariance structure between grazed and mown sites. Reductions in flower and seed production and lower flowering probabilities were the most important vital rates explaining the lower growth rates in grazed sites, whereas these effects were partly buffered by increased germination probabilities.

\section{Acknowledgements}

We would like to thank the late Alex Zeevaert for permission to carry out this research and for help with setting up and maintaining the experiment. HJ and RB were supported by a postdoctoral grant of the Flemish Fund for Scientific Research (FWO) and EJ by the Netherlands Organization for Scientific Research (NWO-veni grant 863.08.006).

\section{References}

Bastrenta, B. et al. 1995. Predicting demographic change in response to herbivory: a model of the effects of grazing and annual variation on the population dynamics of Anthyllis vulneraria. - J. Ecol. 83: 603-611.

Benton, T.G. and Grant, A. 1996. How to keep fit in the real world: Elasticity analyses and selection pressures on life histories in a variable environment. - Am. Nat. 147: 115139.

Brys, R. et al. 2004. The effect of grassland management on plant traits and demographic variation in the perennial herb Primula veris. - J. Appl. Ecol. 41: 1080-1091.

Brys, R. et al. 2005. Effects of habitat deterioration on population dynamics and extinction risks in a previously common perennial. - Conserv. Biol. 19: 1633-1643.

Brys, R. and Jacquemyn, H. 2009. Biological Flora of the British Isles: Primula veris L. - J. Ecol. 97: 581-600.

Brys, R. et al. 2011. Impact of herbivory on flowering behaviour and life history trade-offs in a polycarpic herb: a 10-year experiment. - Oecologia, in press.

Buckley, Y. M. et al. 2010. Causes and consequences of variation in plant population growth rate: a synthesis of matrix population models in a phylogenetic context. - Ecol. Lett. 13:1182-1197.

Caswell, H. 2001. Matrix population models: construction, analysis and interpretation. Sinauer.

Caswell, H. 2010. Life table response experiment analysis of the stochastic growth rate. - J. Ecol. 98: 324-333.

Cohen, J. E. 1977. Ergodicity of age structure in populations with Markovian vital rates. III. Finite-state moments and growth rate; an illustration. - Adv. Appl. Prob. 9: 462-475.

Cohen, J. E. 1979. Comparative statics and stochastic dynamics of age-structured populations. - Theor. Popul. Biol. 16: 159-171

Crawley, M. J. 1983. Herbivory - The Dynamics of Animal-Plant Interactions. - Blackwell Scientific Publications. 
Crone, E. E. et al. 2011. How do plant ecologists use matrix models? - Ecol. Lett. 14: 1-8.

Davison, R. et al. 2010. Demographic effects of extreme weather events on a short-lived calcareous grassland species: Stochastic Life Table Response Experiments (SLTRE). J. Ecol. 98: 255-267.

Doak, D. F. 1992. Lifetime impacts of herbivory for a perennial plant. - Ecology 73: 20862099.

Ehrlén, J. et al. 2005. Land use and population growth of Primula veris: an experimental demographic approach. - J. Appl. Ecol. 42: 317-326.

Franco, M., and Silvertown, J. 2004. A comparative demography of plants based upon elasticities of vital rates. - Ecology 85: 531-538.

García, M.B. and Ehrlén, J. 2002. Reproductive effort and herbivory timing in a perennial herb: fitness components at the individual and population levels. - Am. J. Bot. 89: 1295-1302.

Haridas, C. V. and Tuljapurkar, S. 2005. Elasticities in variable environments: properties and implications. - Am. Nat. 166: 481-495.

Hayes, G. F. and Holl, K. H. 2003. Cattle grazing impacts on annual forbs and vegetation composition of mesic grasslands in California. - Conserv. Biol. 17: 1694-1702.

Jacquemyn, H. et al. 2003. Short-term effects of different management regimes on the response of calcareous grassland vegetation to increased nitrogen. - Biol. Conserv. 111: 137-147.

Jacquemyn, H. et al. 2010a. Seed limitation restricts population growth in shaded populations of a perennial woodland orchid. - Ecology 91: 119-129.

Jacquemyn H. et al. 2010b. Size-dependent flowering and costs of reproduction affect population dynamics in a tuberous perennial woodland orchid. - J. Ecol. 98: 12041215.

Jacquemyn, H. et al. 2011. Management effects on the vegetation and soil seed bank of calcareous grasslands: results from an 11-year experiment. - Biol. Conserv. 144: 416422.

Jongejans, E. et al. 2010. Plant populations track rather than buffer climate fluctuations. Ecol. Lett. 13: 736-743.

Kitagawa, E. M. 1955. Components of a difference between two rates. - J. Am. Stat. Assoc. 50: $1168-1194$.

Lehtilä, K. and Syrjänen, K. 1995. Positive effects of pollination on subsequent size, reproduction, and survival of Primula veris. - Ecology 76: 1084-1098.

Lehtilä, K., and Ehrlén, J. . 2005. Seed size as an indicator of seed quality: a case study of Primula veris. - Acta Oecol. 28: 207-212.

Maron, J. L. and Crone, E. E. 2006. Herbivory: effects on plant abundance, distribution and population growth. - Proc. Roy. Soc. London B 273: 2575-2584.

McNaughton, S. J. 1983. Physiological and ecological implications of herbivory. - In: Lange, O.L. et al. (eds.), Functional Responses to Chemical and Biochemical Environments. Springer-Verlag, pp. 657-678.

Menges, E. S. 2000. Population viability analyses in plants: challenges and opportunities. Trends Ecol. Evol. 15: 51-56.

Mestenhauser, A. 1961. Die Inkulturnahme der Primula veris L. Wechselbeziehungen zwischen Saponin- und Stärkegehalt in der Wurtzel. - Pharmazie 16: 45-49.

Milberg, P. 1994. Germination ecology of the polycarpic grassland perennials Primula veris and Trollius europaeus. - Ecography 17: 3-8.

Obeso, J. R. 2002. The cost of reproduction in plants. - New Phytol. 155: 321-348.

Ornduff, R. 1980. Pollen flow in Primula veris (Primulaceae). - Plant Syst. Evol. 135: 89-93. 
Richards, A. J. \& Ibrahim, H.. 1978. Estimation of neighbourhood size in two populations of Primula veris. - In Richards, A. J. (ed.), The Pollination of Flowers by Insects. Academic Press, pp. 165-174.

Syrjänen, K. and Lehtilä, K. 1993. The cost of reproduction in Primula veris: differences between two adjacent populations. - Oikos 67: 465-472.

Tuljapurkar, S. 1990. Population dynamics in variable environments. Springer.

Tuljapurkar, S. and Orzack, S. H. 1980. Population dynamics in variable environments I: long-run growth rates and extinction. - Theor. Popul. Biol. 18: 314-342.

Wedderburn, F. M. and Richards, A. J.. 1990. Variation in within-morph incompatibility inhibition sites in heteromorphic Primula L. - New Phytol. 116: 149-162.

Wisdom, M. J. et al. 2000. Life stage simulation analysis: estimating vital rate effects on population growth for conservation. - Ecology 81: 628-641.

\section{List of Figures}

Figure 1. Results of the stochastic life table response experiment using the small noise approximation: summed contributions to the stochastic growth rate of mean vital rates $(\Delta \mu)$, variability of vital rates $(\Delta c)$, elasticities $(\Delta e)$ and correlations between vital rates $(\Delta \rho)$ in grazed and mown populations of the perennial grassland herb Primula veris.

Figure 2. a) Decomposition of the differences in stochastic population growth rate $(a)$ of grazed vs. mown populations of the perennial grassland herb Primula veris into contributions by the differences in the vital rate means and b) by the differences in the stochastic components (coefficients of variation of vital rates, vital rate elasticities, and correlations between vital rates) (see Appendix B for all values). $\sigma$ refers to survival, $\gamma$ to growth conditional on survival, and $\varphi$ refers to the probability of a plant flowering in the next year. $\mu$ represents the average number of flowers, $\pi$ the average number of seeds per fruit and $\varepsilon$ the proportion of seeds that germinate and successfully establish as a seedling.

Figure 3. Contributions of differences in temporal correlations between vital rates of the grazed and mown populations. The height and shading indicate the difference in vital rate correlation: the white boxes indicate higher correlation coefficients (indicated with an upward-pointing triangle) in the grazed populations than in the mown populations (bottom of the white box). The grey boxes signal lower correlation coefficients (downward-pointing triangle) in the grazed populations than in the mown populations (top of the grey boxes). The grey horizontal lines correspond to a correlation coefficient level of 0. Maximal positive (1) and negative $(-1)$ correlation coefficient levels are halfway these grey horizontal lines. The width (not the area) of a box is a relative measure of the contribution of the correlation difference to the difference in stochastic population growth rate, $\Delta a$. Please note that increases (white boxes) in correlation coefficients have a negative contribution to $\Delta a$. Symbols are similar as in Figure 2. 
Figure 1.

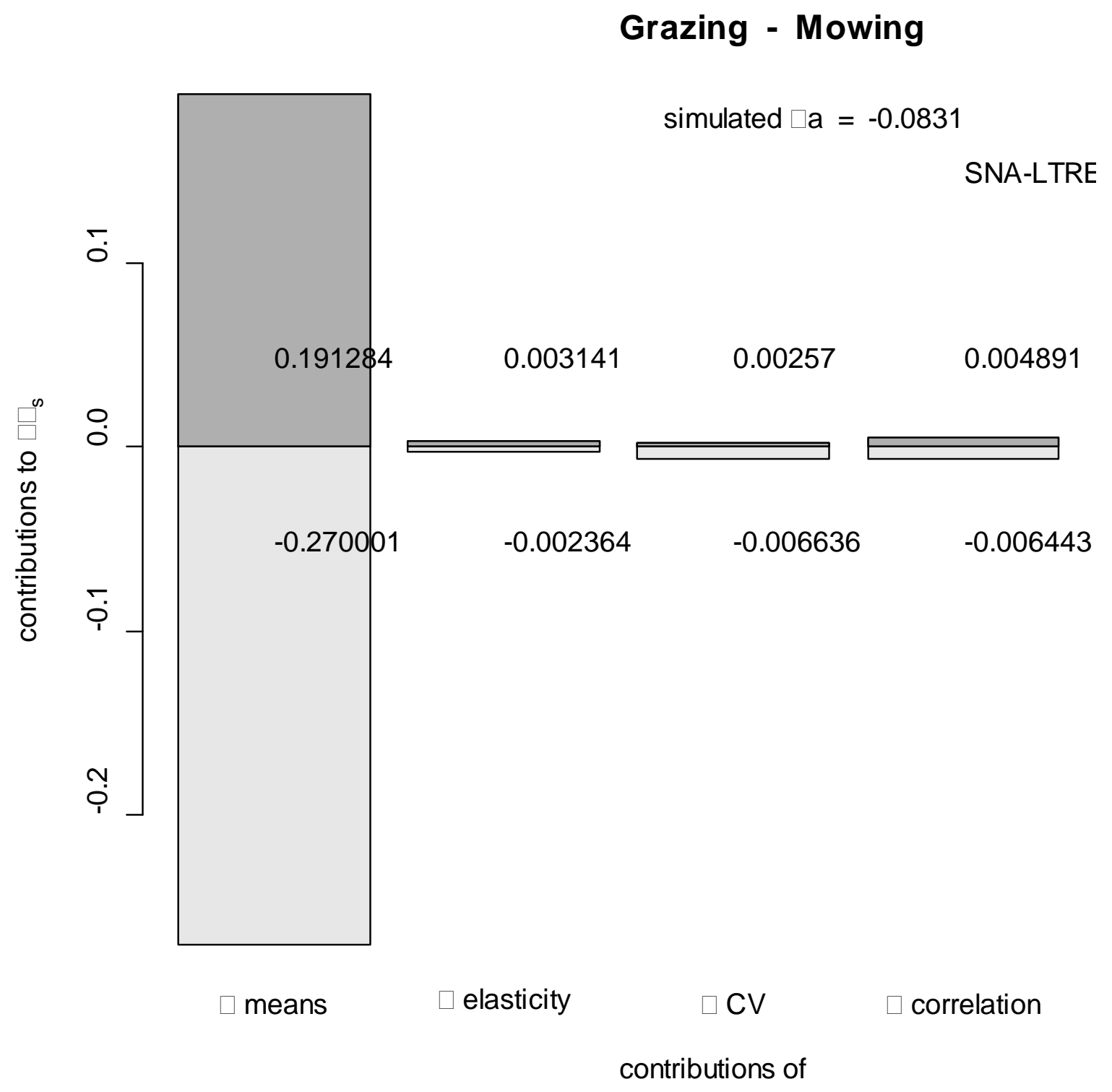


Figure 2.

\section{Grazing - Mowing}

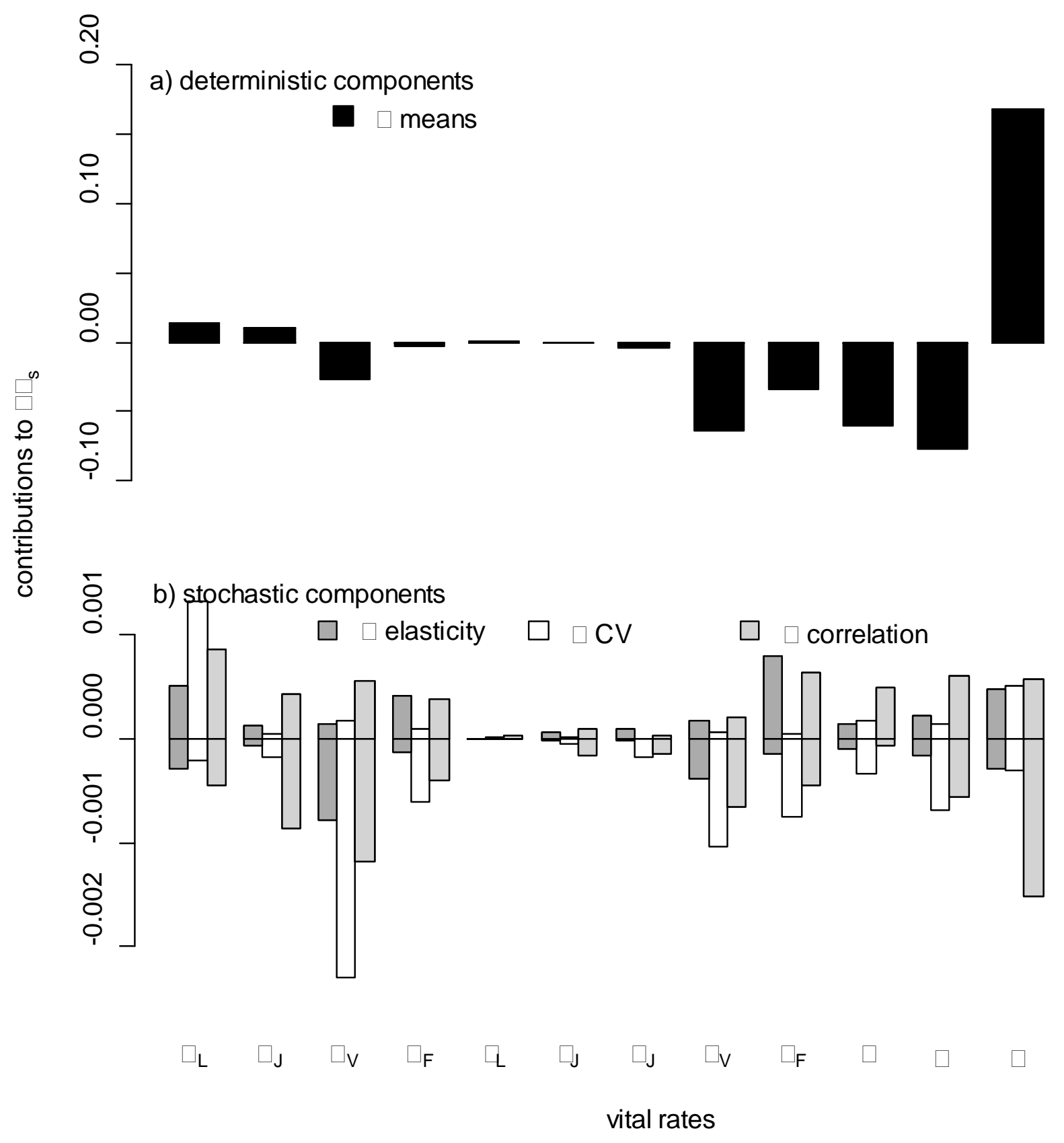


Figure 3.

\section{SNA-LTRE contributions of char}

\section{Legend}

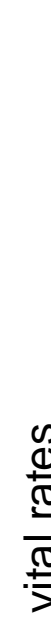

$$
\begin{aligned}
& \square_{\mathrm{L}} \\
& \square_{\mathrm{J}} \\
& \square_{\mathrm{V}} \\
& \square_{\mathrm{F}} \\
& \square_{\mathrm{L}}
\end{aligned}
$$
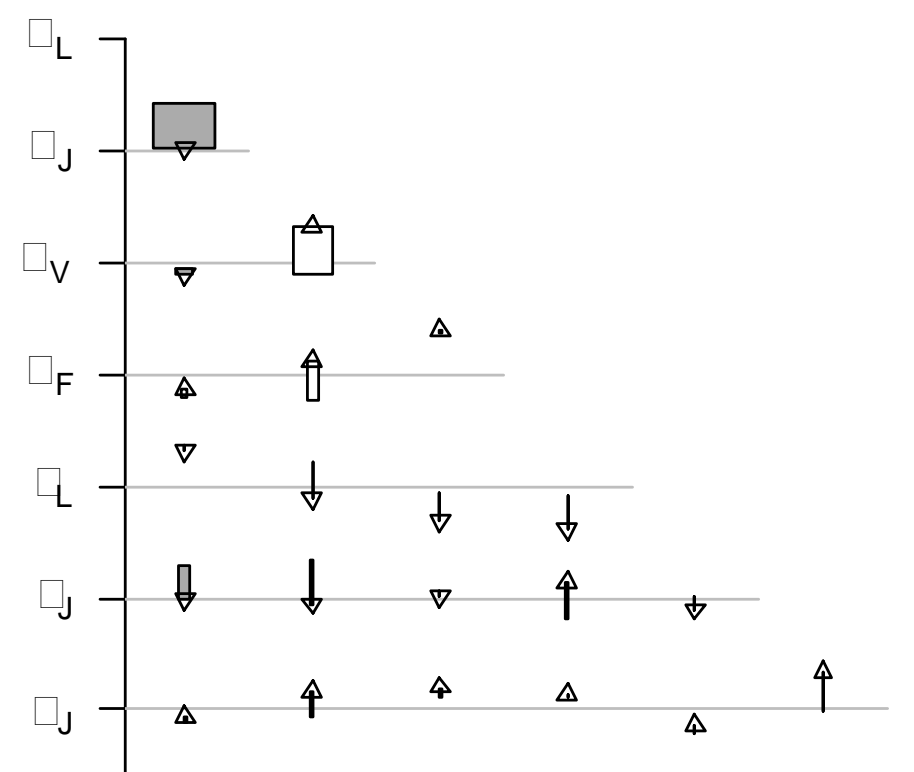

$$
\square \vee
$$$$
\square_{\mathrm{F}}
$$$$
\Delta \quad \Delta \quad \Delta \quad \forall \quad \Delta \quad A \quad \text { 定 }
$$$$
\square
$$

$\square-$
$\square-$
$\square$

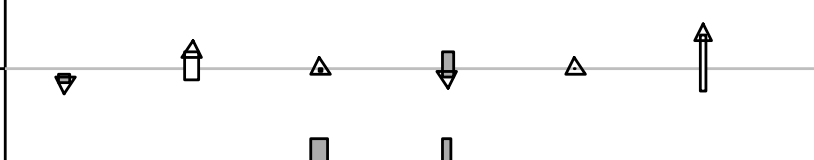

$\Delta \quad \Delta$
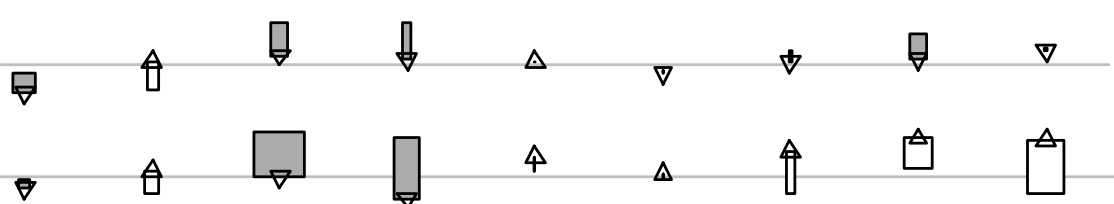

Q
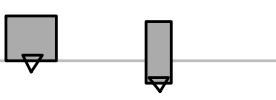

$4 \Delta \quad 0$
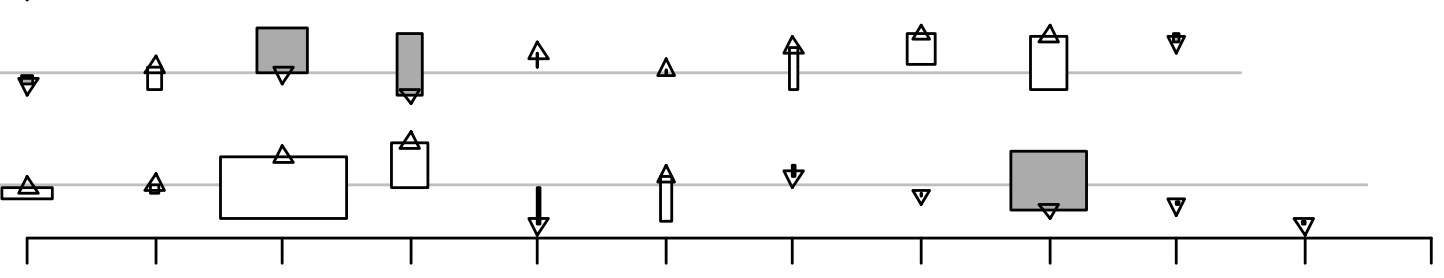

$\square_{\mathrm{L}} \quad \square_{\mathrm{J}} \quad \square_{\mathrm{V}} \quad \square_{\mathrm{F}}$$$
\text { F }
$$

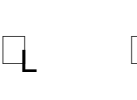

Width grey box: contribution to $a^{\text {grazed }}-a^{\text {mown }}$ is positive (0.00029) because the lower vital $r$ correlation $(\rho)$ in grazed populations increase stochastic growth rate (a) compared to mowr populations.

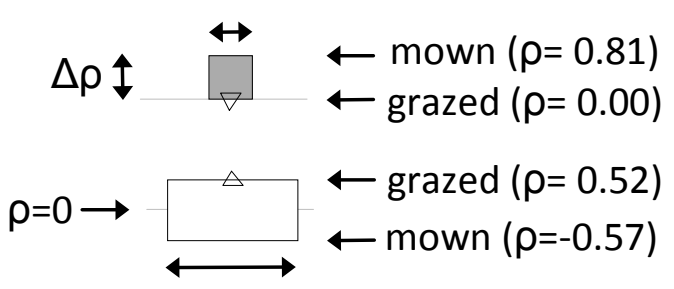

Width white box: contribution to $a^{\text {grazed }}-a^{\text {mow }}$ is negative $(-0.00086)$ because the higher vita correlation $(\rho)$ in grazed populations reduces stochastic growth rate (a) compared to mowr populations

vital rates 
Appendix A. Vital rates used to construct matrix models of mown and grazed Primula veris populations. Data were collected in two sites during ten consecutive years (1999-2008).

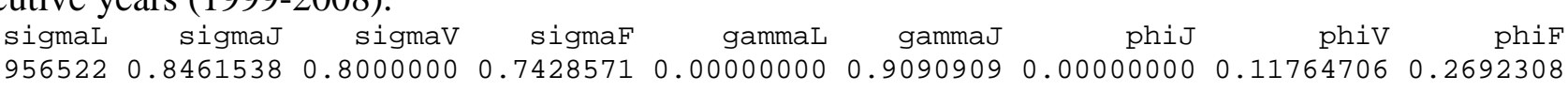

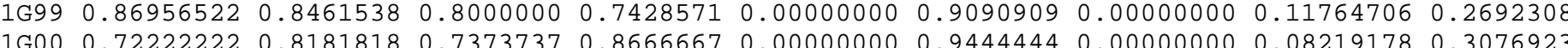

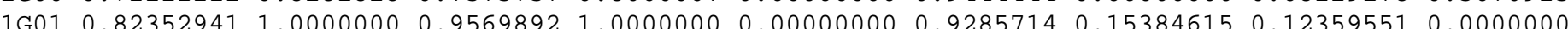

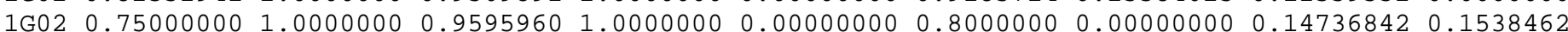

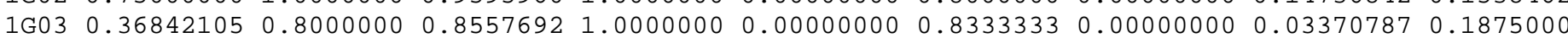
$\begin{array}{lllllllllllll}1 \mathrm{G} 04 & 0.28571429 & 0.6666667 & 0.9174312 & 1.0000000 & 0.00000000 & 1.0000000 & 0.00000000 & 0.15000000 & 0.1666667\end{array}$ $\begin{array}{llllllllll}1 \mathrm{G} 05 & 0.2000000 \odot & 0.7500000 & 0.9270833 & 0.9375000 & 0.00000000 & 0.3333333 & 0.000000000 & 0.17977528 & 0.0000000\end{array}$ $\begin{array}{lllllllllllll}1 \mathrm{G} 06 & 0.30303030 & 1.0000000 & 0.9550562 & 0.9375000 & 0.00000000 & 1.0000000 & 0.25000000 & 0.31764706 & 0.2000000\end{array}$

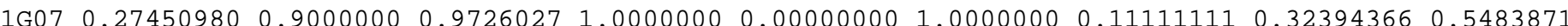

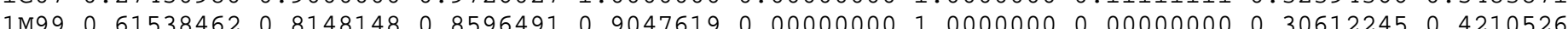

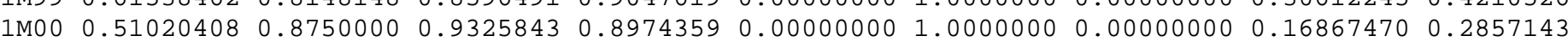
$\begin{array}{llllllllllll}1 M 01 & 0.54545455 & 0.640000 \odot & 0.9405941 & 0.9166667 & 0.00000000 & 1.000000 \odot & 0.37500000 & 0.47368421 & 0.6818182\end{array}$ $\begin{array}{lllllllllll}1 \mathrm{M} 02 & 0.80769231 & 0.6111111 & 0.9701493 & 1.00000000 & 0.00000000 & 1.0000000 & 0.000000000 & 0.38461538 & 0.3787879 & 1.00\end{array}$ $\begin{array}{llllllllllll}1 \mathrm{M} 03 & 0.40909091 & 0.7619048 & 0.9347826 & 1.0000000 & 0.00000000 & 0.8750000 & 0.21428571 & 0.44186047 & 0.8400000\end{array}$ $\begin{array}{lllllllllllll}1 \text { M०4 } & 0.10240964 & 0.5862069 & 0.9253731 & 0.9540230 & 0.0000000 \odot & 0.7647059 & 0.15384615 & 0.48387097 & 0.8915663\end{array}$ $\begin{array}{lllllllllll}1 \text { M05 } & 0.11057692 & 0.7142857 & 0.9807692 & 0.9622642 & 0.0000000 \odot & 1.000000 \odot & 0.20000000 & 0.27450980 & 0.3823529\end{array}$ $\begin{array}{lllllllllllll}1 \text { M06 } & 0.12299465 & 0.6956522 & 0.9553571 & 0.9642857 & 0.00000000 & 0.8750000 & 0.21428571 & 0.66355140 & 0.5555556\end{array}$ $\begin{array}{lllllllllll}1 \text { M07 } & 0.19101124 & 0.6800000 & 0.9577465 & 0.9615385 & 0.000000000 & 0.9411765 & 0.00000000 & 0.72058824 & 0.5300000 & 1.900\end{array}$

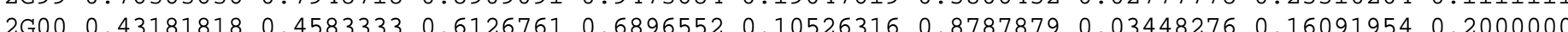

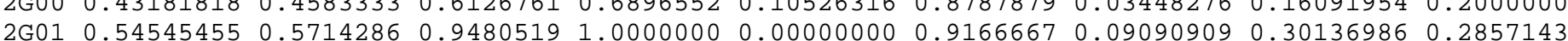
$\begin{array}{lllllllllll}2 \mathrm{GO1} & 0.54545455 & 0.5714286 & 0.9480519 & 1.0000000 & 0.0000000 \odot & 0.9166667 & 0.09090909 & 0.30136986 & 0.2857143 \\ \text { 2G02 } & 0.58974359 & 1.0000000 & 0.9878049 & 1.0000000 & 0.00000000 & 0.8571429 & 0.00000000 & 0.02469136 & 0.0400000\end{array}$

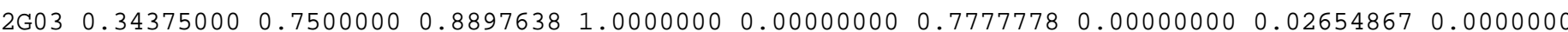

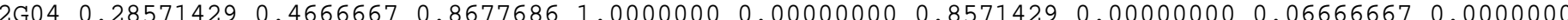

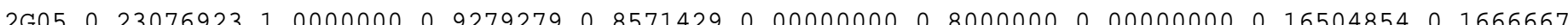

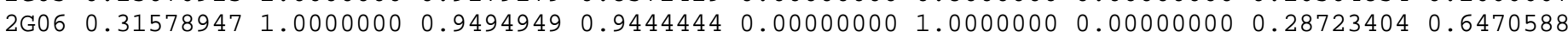

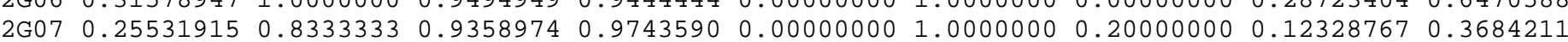
$\begin{array}{lllllllllllll}2 M 99 & 0.84615385 & 0.9200000 & 0.9333333 & 0.8518519 & 0.03030303 & 0.8260870 & 0.13157895 & 0.35714286 & 0.6086957\end{array}$ $\begin{array}{llllllllllllll}2 \text { M०० } & 0.52631579 & 0.8604651 & 0.9560440 & 0.9772727 & 0.00000000 & 0.8918919 & 0.00000000 & 0.21839080 & 0.2093023\end{array}$ $\begin{array}{lllllllllllll}2 M 01 & 0.66666667 & 0.9583333 & 0.9851852 & 1.000000 \odot & 0.000000 \odot \odot ~ & 0.9565217 & 0.18181818 & 0.44360902 & 0.6551724\end{array}$

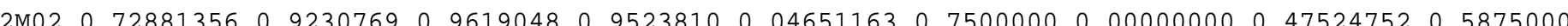
$\begin{array}{lllllllllll}2 \mathrm{M} 03 & 0.48062016 & 0.9318182 & 0.9387755 & 0.9690722 & 0.01612903 & 0.8536585 & 0.11428571 & 0.28260870 & 0.4255319\end{array}$

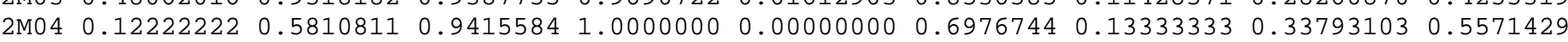
$\begin{array}{lllllllllllll}2 M 05 & 0.09642857 & 0.5217391 & 0.9215686 & 0.9456522 & 0.000000 \odot \odot ~ & 0.6666667 & 0.06250000 & 0.19148936 & 0.3678161\end{array}$ $\begin{array}{lllllllllllll}2 \text { M06 } & 0.22317597 & 0.6857143 & 0.9567568 & 0.9677419 & 0.00000000 & 0.8750000 & 0.14285714 & 0.50847458 & 0.5500000\end{array}$ $\begin{array}{llllllllllll}2 \text { M०7 } & \odot .19191919 & \odot .6181818 & \odot .9166667 & 0.9682540 & 0.0000000 \odot & 0.8823529 & 0.06666667 & 0.38842975 & 0.3606557\end{array}$

mu pi epsilon $\begin{array}{lll}5.54 & 22.77 & 0.004076915\end{array}$ $3.44 \quad 13.56 \quad 0.024296266$ $3.94 \quad 12.45 \quad 0.032617781$ $4.22 \quad 6.36 \quad 0.054455366$ $5.60 \quad 9.710 .016091658$ 4.5412 .170 .030164930 $\begin{array}{lll}5.02 & 15.18 & 0.027065650\end{array}$ $\begin{array}{llll}4.67 & 21.30 & 0.032044515\end{array}$ $\begin{array}{llll}5.67 & 26.73 & 0.016175953\end{array}$ 5.5322 .720 .006190448 $6.0441 .80 \quad 0.003351476$ $10.56 \quad 34.75 \quad 0.002952184$ $\begin{array}{lll}15 & 52.48 & 0.001568303\end{array}$ $8.59 \quad 33.12 \quad 0.011669563$ $8.02 \quad 35.16 \quad 0.008478536$ 9.1238 .120 .005074439 $\begin{array}{llll}8.89 & 34.67 & 0.005156397\end{array}$ $0.07 \quad 40.93 \quad 0.002776147$ $\begin{array}{llll}5.00 & 22.66 & 0.019510382\end{array}$ $4.56 \quad 18.46 \quad 0.004506072$ $4.12 \quad 15.67 \quad 0.086297925$ $\begin{array}{llll}3.89 & 14.89 & 0.022098646\end{array}$ $\begin{array}{llll}4.89 & 13.67 & 0.069811892\end{array}$ $\begin{array}{llll}5.23 & 17.89 & 0.046313763\end{array}$ $\begin{array}{llll}4.82 & 21.67 & 0.025986609\end{array}$ $\begin{array}{llll}5.01 & 18.18 & 0.028667759\end{array}$ $5.1221 .63 \quad 0.027783705$ $5.47 \quad 23.71 \quad 0.010851779$ $\begin{array}{llll}6.04 & 34.57 & 0.001959221\end{array}$ $9.58 \quad 37.46 \quad 0.005669186$ $9.60 \quad 45.37 \quad 0.003525903$ $9.67 \quad 36.75 \quad 0.007832641$ 8.5434 .680 .013505885 $8.9939 .36 \quad 0.007157367$ $9.23 \quad 36.76 \quad 0.004706156$ $9.6640 .86 \quad 0.003217170$ 
Appendix B. Contributions of mean vital rates, variance in vital rates, vital rate elasticities and correlations between vital rates to differences in the stochastic growth rate of grazed and mown sites.

a. contributions of changes in mean vital rates

$\begin{array}{lr}\text { sigmaL } & \odot .0135276913 \\ \text { sigmaJ } & \odot .0 \odot 98908769 \\ \text { sigmaV } & -\odot .0263700967 \\ \text { sigmaF } & -\odot .0033853494 \\ \text { gammaL } & \odot .0003816191 \\ \text { gammaJ } & -\odot .0008416968 \\ \text { phiJ } & -\odot .0 \odot 38412609 \\ \text { phiV } & -\odot .0643659036 \\ \text { phiF } & -\odot .0338492888 \\ \text { mu } & -\odot .0599747165 \\ \text { pi } & -\odot .0773725207 \\ \text { epsilon } & \odot .1674834566\end{array}$

b. contributions of changes in mean vital rate elasticity values

\begin{tabular}{|c|c|c|c|c|c|c|}
\hline & & & & & & \\
\hline & & & & & 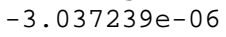 & 1 \\
\hline & $19036 e-05$ & $.012401 \mathrm{e}-05$ & $4.374052 \mathrm{e}-05$ & $87965 e-06$ & $-6.337593 e-08$ & 2.676209 \\
\hline & & 5 & & & & \\
\hline & $28 e-05$ & 4.5 & -05 & & -1 & \\
\hline & $7239 e-\odot 6$ & $-6.337593 e-08$ & $3426 e-06$ & $1.086563 e-06$ & $-1.443056 \mathrm{e}-07$ & 95598 \\
\hline & 05 & 2 . & 3886 & 6 & -2 . & \\
\hline & -8 & & -5 . & & & \\
\hline & & -6 . & -1 & -1 & & \\
\hline & -8.2 & & & -1 & & \\
\hline & -2 . & -6 . & & & & \\
\hline & -1 . & -4 . & -1 & & -5 . & \\
\hline \multirow[t]{2}{*}{ on } & $-5 .=$ & -5 & $170 \mathrm{e}$ & $142 \mathrm{e}-04$ & -06 & $022 \div$ \\
\hline & & & & $\mathrm{mu}$ & D & \\
\hline & -8 & $8 \mathrm{e}$ & -8 & -05 & -05 & \\
\hline & 2. & -6 . & & -6 . & -4 & \\
\hline & -5.5 & -1. & 6 & -1. & -1 & -6 \\
\hline & & $862 e-06$ & -1 & & $289 e-05$ & $-\odot 4$ \\
\hline & & & & -8 & & \\
\hline & & 4. & 033 & -1 . & 96 & -7. \\
\hline & 06 & -5 & & & 06 & 1. \\
\hline & & -2 . & & & -2 & \\
\hline & & & & & & -4 \\
\hline & 2.4 & $-1.002265 e-05$ & $2705 e-05$ & $414 \mathrm{e}-05$ & $2547 e-05$ & $-3.054864 e-05$ \\
\hline & & & & & & \\
\hline & $e-05$ & 7600 & & & 05 & 20691777 \\
\hline
\end{tabular}

c. contributions of changes in coefficients of variance

\begin{tabular}{|c|c|c|c|c|c|c|}
\hline & & si & sig & & & \\
\hline maL & $8092 \mathrm{e}-03$ & $819679 \mathrm{e}-05$ & $1.443885 \mathrm{e}-04$ & $6.899048 \mathrm{e}-05$ & $1.103360 \mathrm{e}-06$ & $95 e-06$ \\
\hline & $9679 e$ & $1310 e-05$ & & & & \\
\hline & $35 e-04$ & & & & & \\
\hline & $6.899048 \mathrm{e}-05$ & $383050 \mathrm{e}-05$ & $-2.786340 \mathrm{e}-\odot 4$ & $-1.439 \odot \odot 9 e-\odot 4$ & $1.819318 \mathrm{e}-06$ & \\
\hline & $3360 \mathrm{e}-06$ & $121 e-07$ & $3992 e-06$ & $9318 e-06$ & & \\
\hline & -06 & $75 e-06$ & & & & \\
\hline & $6581 e-06$ & -2.8 & $3806 e-05$ & -1 & $\odot 7$ & \\
\hline & & -6 . & -2 . & & & \\
\hline & & -1 & & & & \\
\hline & -1.2 & -9. & -8 . & 072 & & \\
\hline & 6 . & & -2 & -3 & & \\
\hline \multirow[t]{2}{*}{ silon } & $906 e-05$ & 100 & $40 e-05$ & -05 & -07 & \\
\hline & & & & $\mathrm{mu}$ & pi & \\
\hline & $6581 \mathrm{f}$ & & 5 & -1 & & \\
\hline & $-2 . \varepsilon$ & -6 & 107 & -9 & 06 & 49 \\
\hline & $-4.318806 \mathrm{e}-05$ & $4759 e-04$ & $662 e-07$ & $7478 e-05$ & $-2.44291 \varepsilon$ & $644 c$ \\
\hline & -1 & -2 . & -2 . & & & \\
\hline & 07 & & -1.2 & & -1 & 36 \\
\hline & $-3.437364 e-06$ & $-9.521280 \mathrm{e}-06$ & $9733 e-06$ & $65540 \mathrm{e}-07$ & $-1.095220 \mathrm{e}-06$ & $1.213233 \epsilon$ \\
\hline & & & & & & \\
\hline & $319 \epsilon$ & $058 \mathrm{e}$ & $7478 e-04$ & 8121 & -1.2 & \\
\hline & -4 & $-2.047478 e-04$ & $-3.534037 \mathrm{e}-04$ & -1.374693 & $-5.950966 \mathrm{e}$ & Pח \\
\hline & & & & & & \\
\hline
\end{tabular}


pi $\quad-4.673539 \mathrm{e}-06-1.229304 \mathrm{e}-04 \quad-5.950966 \mathrm{e}-05 \quad 1.630763 \mathrm{e}-05 \quad-2.153610 \mathrm{e}-04 \quad 1.036724 \mathrm{e}-04$ epsilon -1.143119e-05 3.281201e-05 -3.750041e-05 $-8.781959 \mathrm{e}-05 \quad 1.036724 \mathrm{e}-04 \quad 3.431485 \mathrm{e}-04$

d. contributions of changes in correlation coefficients

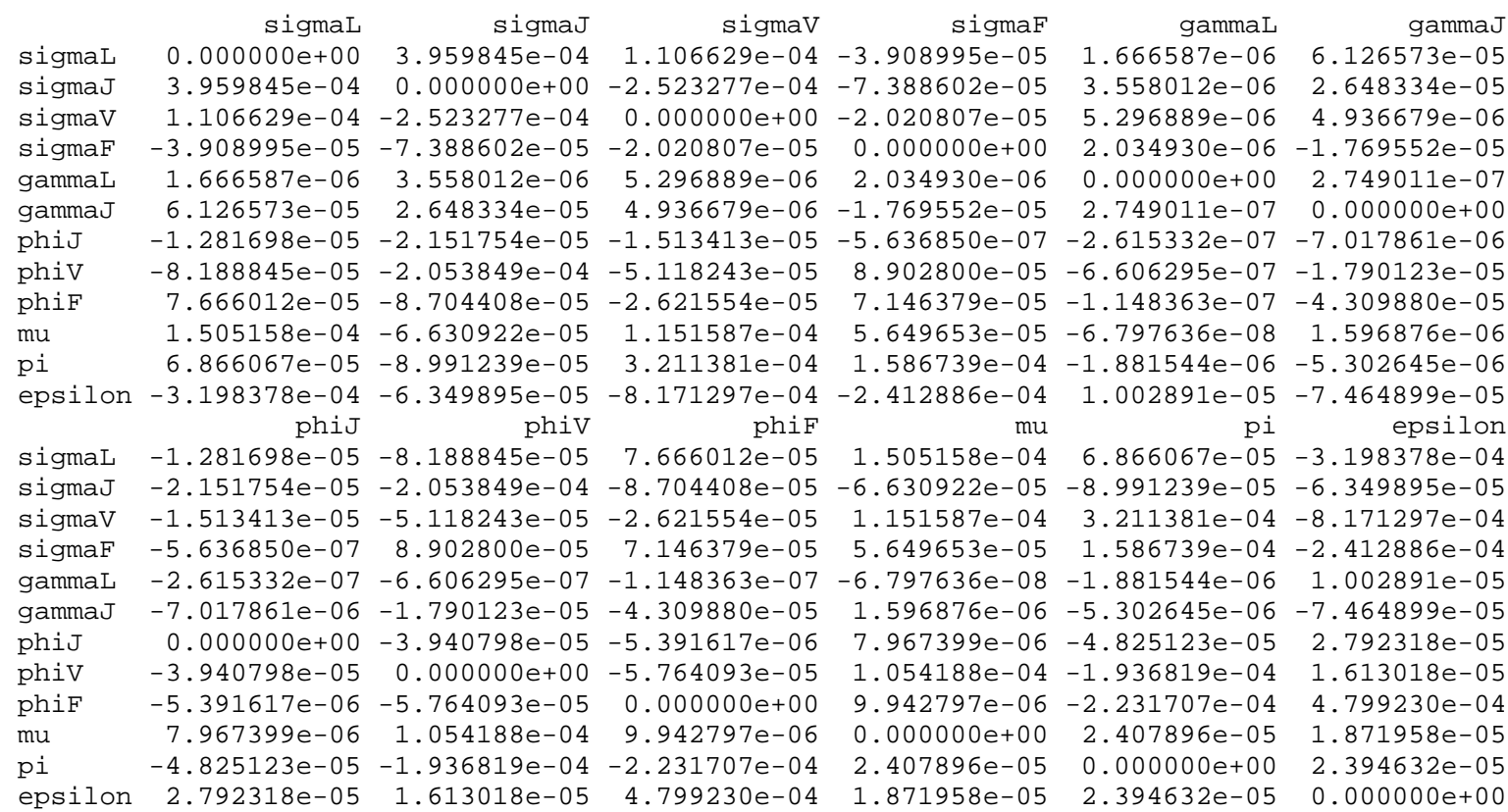

Appendix C. SNA-LTRE analysis of the difference in stochastic population growth rate between site 2 and site 1 .

Site 2 - Site 1

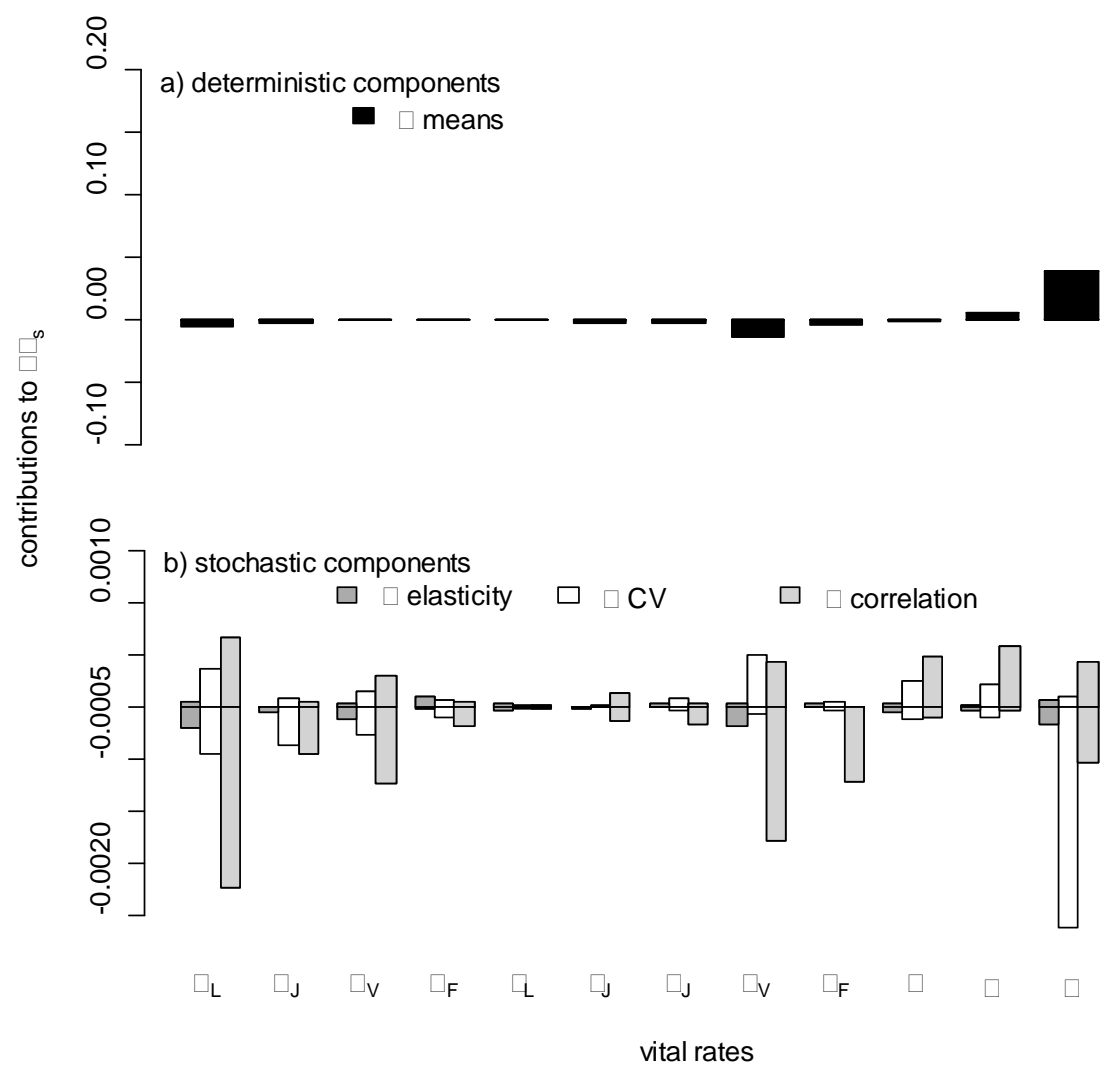

